Supporting information

\title{
Qualitative and quantitative evaluation of sulfur containing compound types in heavy crude oil and its fractions
}

\author{
Alessandro Vetere ${ }^{\dagger}$, Daniel Pröfrock ${ }^{\star}$ and Wolfgang Schrader ${ }^{\dagger *}$ \\ $\dagger^{\dagger}$ : Max-Planck-Institut für Kohlenforschung, Kaiser-Wilhelm-Platz 1, D-45470 Mülheim/Ruhr, Germany \\ ¥: Helmholtz Zentrum Hereon, Institut für Umweltchemie des Küstenraums, Max-Planck-Straße 1, D-21502 \\ Geesthacht, Germany
}

Table of Contents

FIRST IMPLEMENTATION OF AN HPLC-FTMS COUPLING FOR SULFUR SELECTIVE SEPARATION OF CRUDE OIL

IONIZATION BEHAVIOR OF REFERENCE COMPOUNDS UNDER THE GIVEN CONDITIONS IN HPLCAPPI-FTMS

PREPARATION OF STATIONARY PHASE AND HPLC COLUMNS .5

OPERATION PRINCIPLE OF SULFUR SPECIFIC DETECTION BY ICP-MS/MS ..................................5

CALIBRATION OF ICP-MS/MS FOR QUANTIFICATION OF SULFUR ..........................................

QUANTITATIVE RESULTS OF SULFUR CONTENT FROM HPLC-ICP-MS/MS ...................................

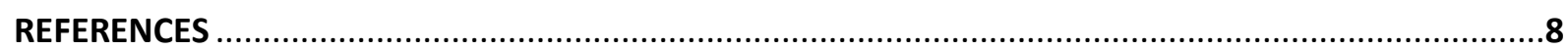




\section{FIRST IMPLEMENTATION OF AN HPLC-FTMS COUPLING FOR SULFUR SELECTIVE SEPARATION OF CRUDE OIL}

Figure S1 shows results from a first implementation of an online HPLC-FTMS coupling using the original LC protocol developed by Andersson and co-workers ${ }^{1-4}$ applying an Orbitrap scan rate of $2 \mathrm{~Hz}$, yielding a mass resolution of $R=120,000$ (FWHM at $\mathrm{m} / \mathrm{z} 400$ ). The lower panel shows the heteroatom class distributions for the assigned signals throughout the corresponding peaks (summarization limits are highlighted on the upper panel).

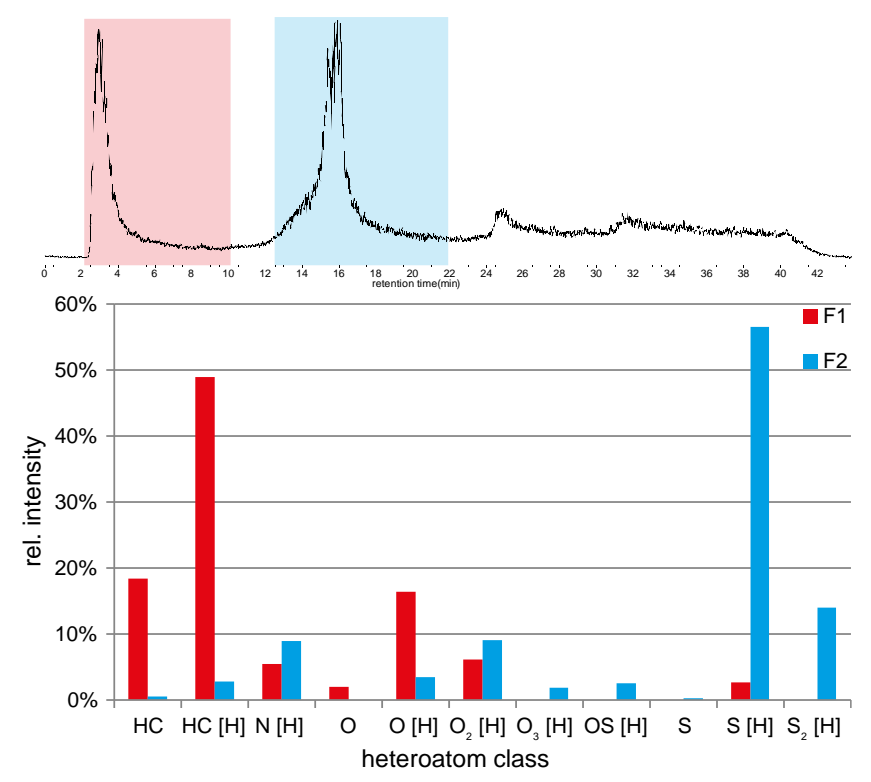

Figure S1. Total ion chromatogram (TIC) recorded from HPLC-FTMS analysis of a heavy crude oil, using the original protocol published by Andersson and co-workers (top). Class distributions of the first (red) and second (blue) chromatographic peak are shown in the bottom panel.

A good separation of sulfur free hydrocarbons (first peak, red) and sulfur containing thiophenic compounds (second peak, blue) can be observed. Acknowledging the limitation of noncondensed thiophenes within the first and of $\mathrm{S}_{2}$-compounds in within the second fraction, these results also show an additional benefit of the method. By the chromatographic separation of the majority of sulfur-free and sulfur containing compounds it reduces the need for utmost mass resolving power, as large portions of the most problematic isobars $\left(\Delta m=3.4 \mathrm{mDa}\right.$ between $\mathrm{C}_{3}$ and $\mathrm{SH}_{4}$ ) are now chromatographically separated from each other. This could enable a deeper analysis of crude oil and related samples, also when only less resolving mass spectrometers, such as Time-of-Flight instruments are available. 


\section{IONIZATION BEHAVIOR OF REFERENCE COMPOUNDS UNDER THE GIVEN CONDITIONS IN HPLC-APPI-FTMS}

To verify the behaviour of analytes during ionization for HPLC-APPI-FTMS experiments, a set of reference compounds has been analysed using the solvent compositions used during the chromatographic runs.

Compounds used include:

benzo[b]thiopnene (BT), phenylisopropylsulfide (PhiPrS), methyloctylsulfide (MeOctS), 4,6dimethyldibenzothiophene (DMDBT), benzo[a]dibenzothiophene (BNT) and dibenzyldisulfide (Bn2S2)

Several ion species are observed, as discussed below for all analytes. Most importantly, hydride abstraction and in-source oxidation are observed as dominant processes for fully aliphatic sulfides.

\section{Protonated molecules $\left([\mathrm{M}+\mathrm{H}]^{+}\right)$}

Protonated molecules are observed in all cases, but generally stay in a region of $1-10 \%$ signal intensity compared to the corresponding radical ion (see Figure S2 (a)). Exceptions to this rule are completely aliphatic sulfides, where the proton adduct is the dominating species. With increasing amount of THF this ion goes down in intensity, while the oxygenated form strongly increases (see Figure S2 (c)).

\section{Hydride abstractions $\left([\mathrm{M}-\mathrm{H}]^{+}\right)$}

Hydride abstractions are observed for sulfidic species only (see Figure S2 (b)). For all other compounds the corresponding signal intensity was (if present at all) below $0.1 \%$ compared to the corresponding radical ion. The overall intensity ratio towards the radical ion stays relatively stable with increasing THF amount. From 15\% THF onwards the amount drops for fully aliphatic sulfides, favoring the oxidized product (see Figure S2 (c)).

\section{Oxidized product molecules $\left([\mathrm{M}+\mathrm{O}+\mathrm{H}]^{+}\right)$}

In-source oxidation is observed for all species and on all THF levels (see Figure S2 (c)). For most compounds though, it remains at levels below $10 \%$ relative intensity compared to the radical ion. Only exception is the fully aliphatic sulfide. Here the oxidized product is already of relevant intensity without any THF. The Signal intensity increases dramatically with additional THF to form the dominating ion species for this compound. 
a)

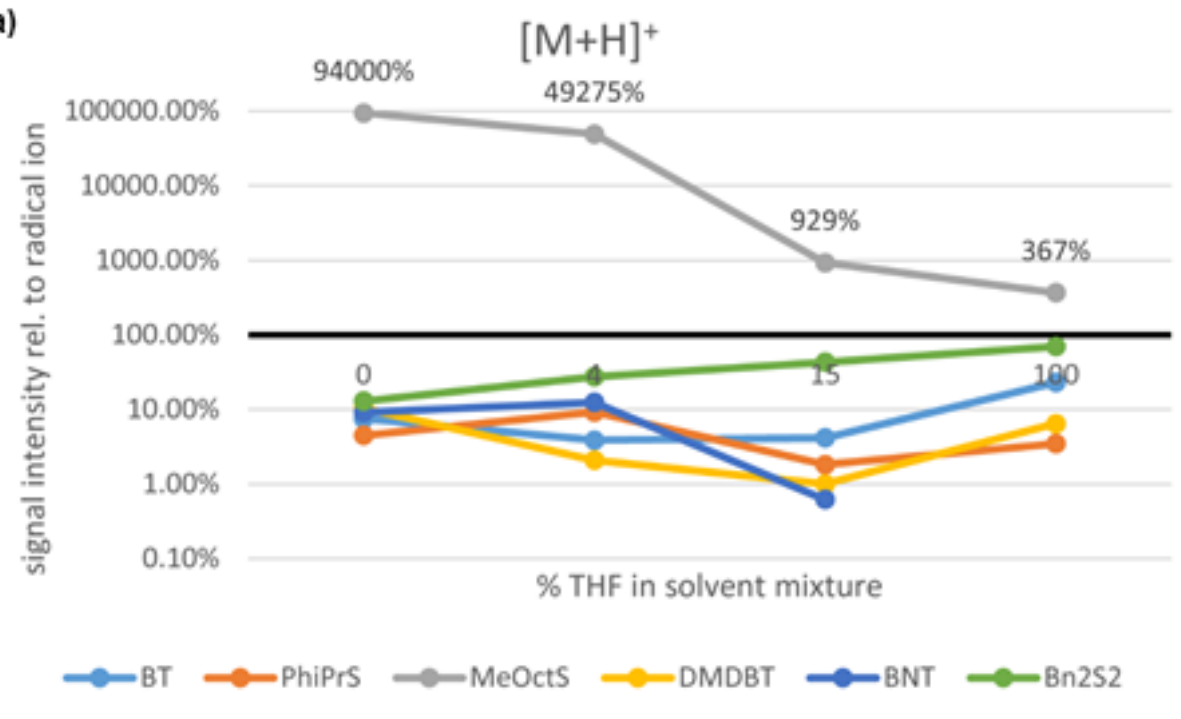

b)

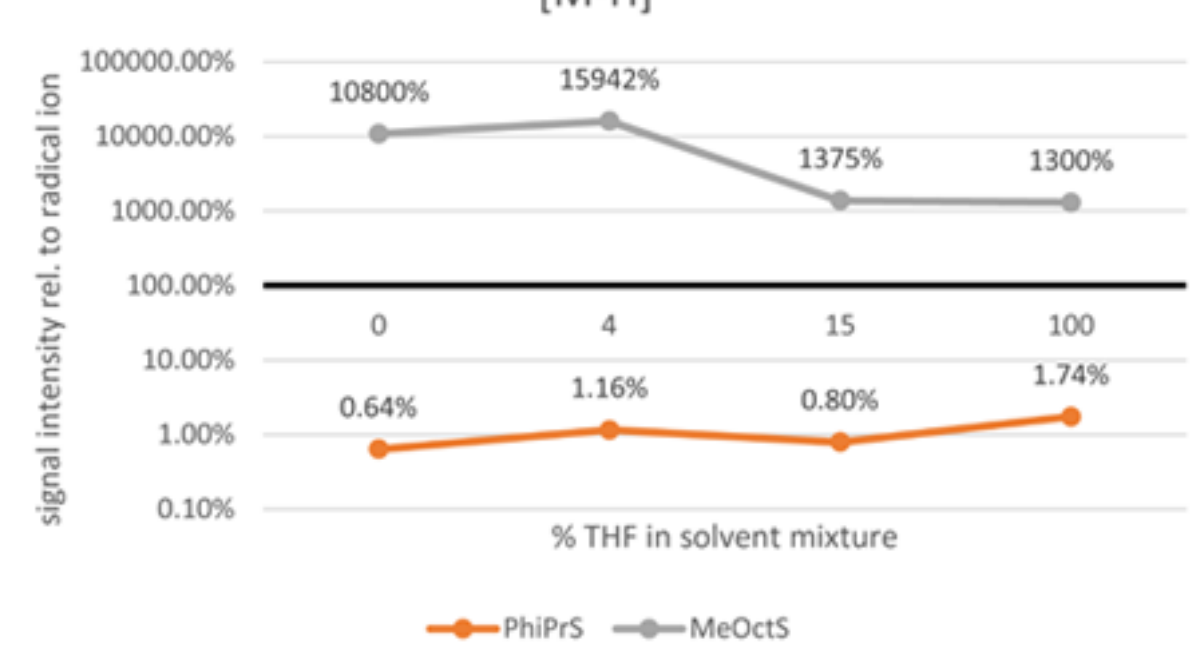

c)

\section{$[\mathrm{M}+\mathrm{O}+\mathrm{H}]^{+}$}
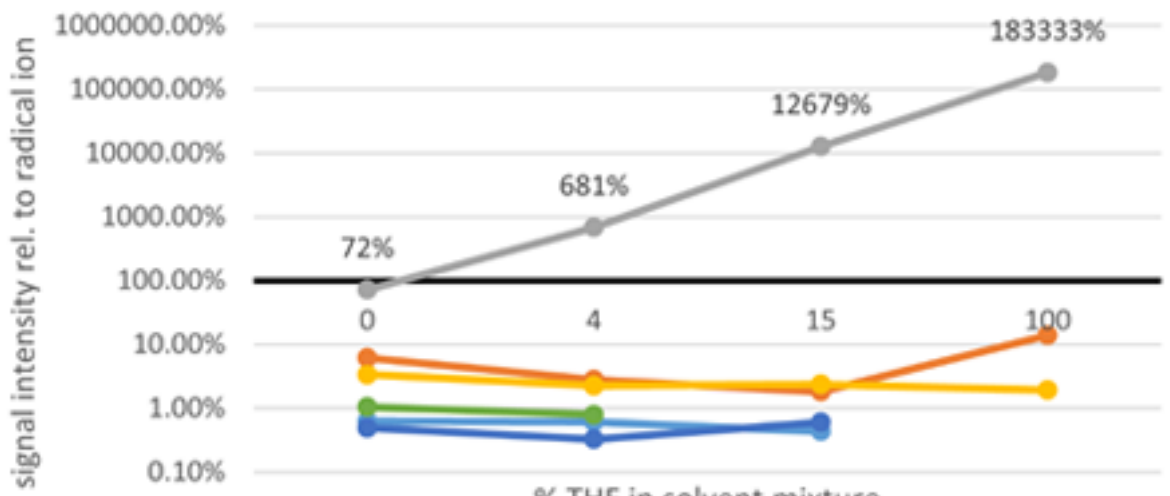

$\%$ THF in solvent mixture

$\multimap \mathrm{BT} \longrightarrow \mathrm{PhiPrS} \longrightarrow \mathrm{MeOcts} \longrightarrow \mathrm{DMDBT} \longrightarrow \mathrm{BNT} \longrightarrow \mathrm{Bn} 2 \mathrm{~S} 2$

Figure S2. Signal intensity of protonated molecules (a), hydride abstracted molecules (b) and oxidized protonated molecules (c) of reference compounds relative to the corresponding radical ion. 


\section{PREPARATION OF STATIONARY PHASE AND HPLC COLUMNS}

The stationary phase for ligand exchange chromatography (Pd-MPSG) was prepared based on the protocol by Andersson and co-workers. ${ }^{3}$ Briefly, silica gel (10 g, LiChrosorb ${ }^{\circledR}$ Si 100, $10 \mu \mathrm{m}$, Merck KgAA, Darmstadt, Germany), was dried for $24 \mathrm{~h}$ at $240{ }^{\circ} \mathrm{C}$ and then suspended in dry toluene $(50 \mathrm{~mL})$. 3-Mercaptopropyltrimethoxysilane $(18 \mathrm{~mL})$ was added and the mixture was refluxed under argon for $24 \mathrm{~h}$. The colorless mercaptopropano modified silica gel (MPSG) was then filtered off, washed consecutively with toluene and methanol (100 mL each) and stored at $50{ }^{\circ} \mathrm{C}$ overnight.

Palladium loading was performed by suspending MPSG $(6 \mathrm{~g})$ in water $(50 \mathrm{~mL})$ and adding $\mathrm{PdCl}_{2}(1 \mathrm{~g})$. The mixture was vigorously stirred for $1 \mathrm{~h}$, during which the color changed from brownish to red. The Pd-loaded silica gel (Pd-MPSG) was then filtered off, washed with water $(100 \mathrm{~mL})$ and acetone $(50 \mathrm{~mL})$ and stored at $50{ }^{\circ} \mathrm{C}$ overnight to give the final stationary phase as an orange-red powder.

HPLC columns $(2 \times 250 \mathrm{~mm})$ were prepared by wet-packing the prepared stationary phase (slurry in propan-2-ol) using a pneumatic pump (Smartline 1950, Knauer Wissenschaftliche Geräte $\mathrm{GmbH}$, Berlin, Germany) at a packing pressure of 400 bar.

\section{OPERATION PRINCIPLE OF SULFUR SPECIFIC DETECTION BY ICP-MS/MS}

For the quantification of sulfur by ICP-MS/MS a triple quadrupole setup can be run in selected reaction monitoring (SRM) mode (see Figure S3). In the first quadrupole stage ions of $\mathrm{m} / \mathrm{z} 32$ $\left(\mathrm{S}^{+}\right.$and interfering $\mathrm{O}_{2}{ }^{+}$species) are selected and transmitted to the reaction cell, where they are reacted with oxygen gas. Thus, sulfur is oxidized to form $\mathrm{SO}^{+}$ions, which are detected at $\mathrm{m} / \mathrm{z}$ 48 by the second quadrupole. Thus the transition of the main isotope $m / z 32 \rightarrow 48$ is monitored, effectively avoiding any polyatomic interferences. ${ }^{5-7}$

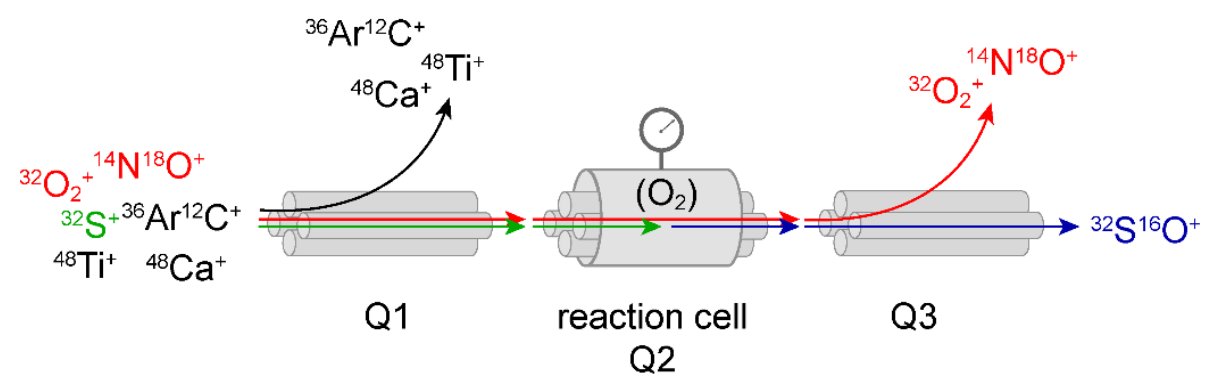

Figure S3. Operation principle of ICP-MS/MS in the $\mathrm{O}_{2}$ mass shift mode for sulfur detection. Q1 is set to allow the transition of all ions with $\mathrm{m} / \mathrm{z} 32$, while all other ions, which show the same nominal mass as the targeted reaction product $\left({ }^{48} \mathrm{SO}^{+}\right)$are rejected. Inside the cell ${ }^{32} \mathrm{~S}^{+}$reacts with $\mathrm{O}_{2}$ to form its oxide, while the interfering ${ }^{16} \mathrm{O}_{2}{ }^{+}$dimer does not indicate any reactivity. Q3 is finally set to allow only the transition of $\mathrm{m} / \mathrm{z} 48$, while all other masses are rejected, which allows the sensitive, interference free determination of sulfur using its main isotope ${ }^{32} \mathrm{~S}$. 


\section{CALIBRATION OF ICP-MS/MS FOR QUANTIFICATION OF SULFUR}

Calibration of the instrument was performed on the same day of measurement using loopinjections into a continuous flow of mobile phase. As calibrant dibenzothiophene in cyclohexane/toluene (9:1) was used at concentrations of $0.171,0.341,0.853$ and $1.705 \mu \mathrm{g} \mathrm{ml}^{-1}$. $20 \mu \mathrm{L}$ were injected, resulting in total amounts of sulphur per injection of 3.41, 6.82, 17.1 and $34.1 \mathrm{ng}$, respectively. All concentration levels were injected in triplicates to give final regression curves as given in Figure S4.
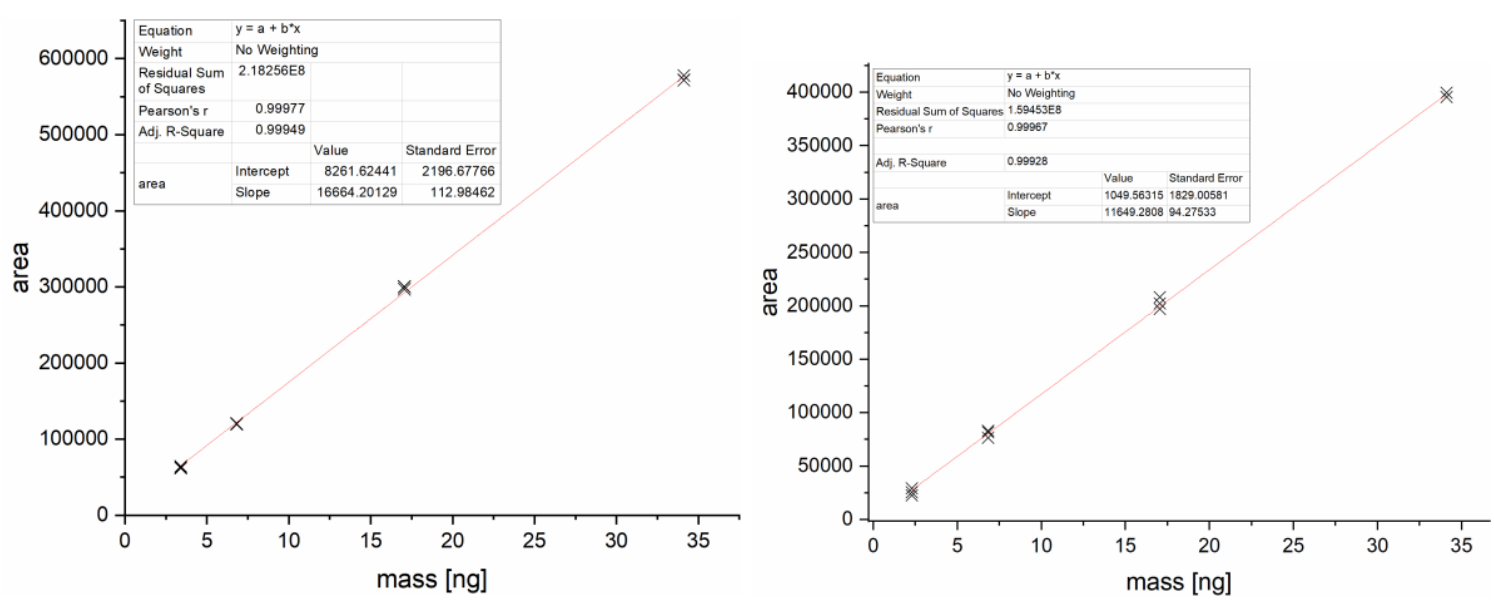

Figure S4. Regression curves obtained for calibration, using obtained signal vs. total mass injected sulphur. The graphs display calibration data from two consecutive days on which the data for this study was recorded. 
Table S1. Mass balance of SARA fractionation and results of sulfur quantification. Total S content is calculated based on loop injection experiments. Values are given as mass fraction within the given fraction as well as regarding the whole crude oil. Mass fractions $w_{\mathrm{Pdx}}$ are calculated from HPLC-ICPMS/MS analysis, with LC recovery being calculated based on the findings of loop injections.

\begin{tabular}{|c|c|c|c|c|c|c|c|c|}
\hline \multirow{3}{*}{ sample } & $w$ & \multicolumn{2}{|c|}{ total $\mathrm{S}$} & $w_{\mathrm{F} 1}(\mathrm{~S})$ & $w_{\mathrm{F} 2}(\mathrm{~S})$ & $w_{\mathrm{F} 3}(\mathrm{~S})$ & $w_{\mathrm{F} 1-3}(\mathrm{~S})$ & LC \\
\hline & wt- $\%$ & \multicolumn{2}{|c|}{ wt- $\%$} & wt-\% & wt- $\%$ & wt-\% & wt- $\%$ & $\%$ \\
\hline & SARA & fraction & crude & LC-ICP & LC-ICP & LC-ICP & LC-ICP & LC-ICP \\
\hline $\begin{array}{l}\text { whole } \\
\text { crude }\end{array}$ & 100 & \multicolumn{2}{|c|}{$3.34(2)$} & 0.019 & 1.47 & 2.39 & 3.87 & 116.0 \\
\hline saturates & 8.834 & $0.036(2)$ & 0.003 & 0.006 & 0.025 & 0.004 & 0.036 & 99.3 \\
\hline aromatics & 52.632 & $3.91(2)$ & 2.06 & 0.020 & 1.81 & 0.951 & 2.78 & 71.1 \\
\hline resins I & 8.973 & $4.74(3)$ & 0.425 & 0.041 & 0.501 & 0.478 & 1.02 & 21.5 \\
\hline resins II & 5.924 & $4.76(13)$ & 0.282 & 0.013 & 0.291 & 0.371 & 0.675 & 14.2 \\
\hline asphaltenes & 11.245 & $3.32(13)$ & 0.373 & 0.018 & 0.292 & 0.264 & 0.575 & 17.3 \\
\hline$\Sigma_{\text {fractions }}$ & 87.607 & 3.59 & 3.14 & 0.020 & 1.20 & 0.680 & 1.90 & 52.9 \\
\hline
\end{tabular}




\section{REFERENCES}

1. Muller, H.; Adam, F. M.; Panda, S. K.; Al-Jawad, H. H.; Al-Hajji, A. A., Evaluation of Quantitative Sulfur Speciation in Gas Oils by Fourier Transform Ion Cyclotron Resonance Mass Spectrometry: Validation by Comprehensive Two-Dimensional Gas Chromatography. $J$. Am. Soc. Mass. Spectrom. 2012, 23 (5), 806-815.

2. Moustafa, N. E.; Andersson, J. T., Analysis of polycyclic aromatic sulfur heterocycles in Egyptian petroleum condensate and volatile oils by gas chromatography with atomic emission detection. Fuel Processing Technology 2011, 92 (3), 547-555.

3. Japes, A.; Penassa, M.; Andersson, J. T., Analysis of Recalcitrant Hexahydrodibenzothiophenes in Petroleum Products Using a Simple Fractionation Process. Energy \& Fuels 2009, 23 (4), 2143-2148.

4. Panda, S. K.; Schrader, W.; al-Hajji, A.; Andersson, J. T., Distribution of Polycyclic Aromatic Sulfur Heterocycles in Three Saudi Arabian Crude Oils as Determined by Fourier Transform Ion Cyclotron Resonance Mass Spectrometry. Energy \& Fuels 2007, 21 (2), 10711077.

5. Bouyssiere, B.; Leonhard, P.; Pröfrock, D.; Baco, F.; Lopez Garcia, C.; Wilbur, S.; Prange, A., Investigation of the sulfur speciation in petroleum products by capillary gas chromatography with ICP-collision cell-MS detection. Journal of Analytical Atomic Spectrometry 2004, 19 (5), 700-702.

6. Pröfrock, D.; Leonhard, P.; Prange, A., Determination of sulfur and selected trace elements in metallothionein-like proteins using capillary electrophoresis hyphenated to inductively coupled plasma mass spectrometry with an octopole reaction cell. Analytical and Bioanalytical Chemistry 2003, 377 (1), 132-139.

7. Pröfrock, D.; Leonhard, P.; Wilbur, S.; Prange, A., Sensitive, simultaneous determination of $\mathrm{P}, \mathrm{S}, \mathrm{Cl}, \mathrm{Br}$ and I containing pesticides in environmental samples by $\mathrm{GC}$ hyphenated with collision-cell ICP-MS. Journal of Analytical Atomic Spectrometry 2004, 19 (5), 623-631. 